\title{
Survey of European Pain Medicine Practice
}

Sanjeeva Gupta, MD, FRCA, FFPMRCA 1 , Manish Gupta, FRCA², Sherdil Nath, MD, FRCA ${ }^{3}$, and G. Michael Hess, MD4

From: ${ }^{1}$ Bradford Teaching Hospitals NHS Foundation Trust; ${ }^{2}$ Walton Centre NHS Trust, Liverpool, England; ${ }^{3}$ The Pain Clinic, Sweden; ${ }^{4} \mathrm{OCM}$ - Orthopaedische Chirurgie Muenchen, Munich, Germany

Dr. S Gupta is a consultant in Pain Medicine and Anesthesia. Dr. M. Gupta is Speciality Registrar in Pain Medicine with the Walton Centre NHS Trust, Liverpool England. Dr. Nath is a consultant in pain medicine. Dr. Hess is a consultant in orthopaedic Spine Surgery and pain medicine

Address Correspondence: Manish Gupta FRCA, Walton Centre NHS Trust Department of Pain Medicine Lower Lane, Fazakerley, Liverpool, United Kingdom

E-mail: manishg_mamc@hotmail. com;guptam@doctors.net.uk

Disclaimer: There was no external funding in the preparation of this manuscript. Conflict of interest: None.

Disclosure: The information contained in this manuscript was presented by Dr. S. Gupta as a keynote lecture at the Annual

Meeting of the American Society of Interventional Pain Physicians, June 2011 in Washington, DC.

Manuscript received: $04 / 27 / 2012$ Revised manuscript received: 06/18/2012 Accepted for publication: $07 / 19 / 2012$

Free full manuscript: www.painphysicianjournal.com
This survey was undertaken to explore the variation in the functional constitution of pain clinics in Europe. In addition, we also explored the amount of training which doctors practicing pain medicine typically receive. Approximate hospital charges for common pain interventions and the source of funding were also surveyed. Members of the British Pain Society (Interventional Pain Medicine-Special Interest Group) and other pain physicians in Europe responded through the online questionnaire tool "Survey Monkey." About 215 requests were sent; 82 pain practitioners from 13 countries in Europe responded. This survey indicates that chronic pain interventions are primarily funded either through government or insurance companies. The primary chronic pain service members continue to be anesthesiologists, combined with specialist nurses and physiotherapists. There appears to be some consistency, both with regard to working in a multidisciplinary team, and the training required to become a pain specialist. More than half of the respondents reported the cost of common interventions like caudal epidural steroid injection (ESI), transforaminal ESI, 3 level medial branch blocks, and 6 level facet joint injections to fall under the $€ 500$ range (\$645). Two thirds of the respondents reported the cost of 4 -joint radiofrequency lumbar denervation to be less than $€ 1,500$ (\$1,935). Good practice should ensure an adequate duration of training, and development of a pain faculty to ensure standards of assessments across the continent. A more detailed, large scale survey is perhaps required to map the availability of chronic pain services and understand the health economics in pain medicine across Europe.

Key words: Chronic pain, Europe, survey, charges for pain interventions, advanced training, multidisciplinary pain team, pain specialists

Pain Physician 2012; 15:E983-E994 hronic pain is one of the most significant causes of suffering in Europe, and has a significant Jeconomic impact through those affected being unable to work. Epidemiological studies show that up to one in 7 people in the United Kingdom (UK) population have chronic pain; it strikes one in $5(19 \%)$ adults across Europe $(1,2)$. It has been estimated that back pain alone

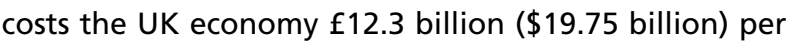

year (3). The lifetime prevalence of back pain in Europe has been estimated at between $59 \%$ and $90 \%$. In any one year, the incidence of back pain is reported to be approximately $5 \%$ of the population (4). Back pain is the second leading cause of sick leave. In the UK, $12.5 \%$ of all sick days were found to be related to low back disorders. Figures for Sweden are similar, with an estimated $13.5 \%$ of sick days said to be the result 
of lower back problems (5). The economic cost of back pain to society in the Netherlands has been estimated to be $1.7 \%$ of the gross national product (6). American data from multiple studies have shown an incidence of recurrent or chronic low back pain at 3 months, 6 months, and 12 months to range from $35 \%$ to $79 \%$ (7).

In July 2009, the American Society of Interventional Pain Physicians (ASIPP) published a review of current evidence regarding interventional techniques and the management of chronic spinal pain. The recommendations by ASIPP are: $1 \mathrm{~A}$ or $1 \mathrm{~B} /$ strong evidence for caudal epidural steroid injections for lumbar spinal pain with disc herniation and radiculitis or discogenic pain without disc herniation or radiculitis; 1B or $1 \mathrm{C} /$ strong evidence for caudal epidural injection in the management of patients with postlumbar laminectomy syndrome and spinal stenosis; $1 \mathrm{C}$ for blind lumbar interlaminar epidural for disc herniation and radiculitis; 2C/very weak evidence for spinal stenosis and discogenic pain without disc herniation and radiculitis (8). Systematic reviews have also concluded that the evidence for pain relief with radiofrequency neurotomy of medial branch nerves is moderate to strong in the cervical and lumbar spine (9). Regarding transforaminal epidurals, a recent systematic review concluded that the evidence is good for radiculitis secondary to disc herniation with local anesthetics and steroids and fair with local anesthetic only; it is fair for radiculitis secondary to spinal stenosis with local anesthetic and steroids; and limited for axial pain and postsurgery syndrome using local anesthetic with or without steroids (10). Hence, it seems appropriate to also attempt an accurate assessment in monetary terms of the current burdens imposed by common interventions for spinal pain on patients and a country's health care system.

Chronic pain may not be a life-threatening condition, but it constitutes a major public health problem in Europe and has assumed epidemic proportions. This substantial epidemiological and economic impact of chronic pain on society is expected to increase further, due to a combination of changing attitudes and expectations, changing methods of medical management and changing social provision. Despite this, the provision of specialist services to manage chronic pain in Europe is highly variable. There is a wide variation in the availability of services from country to country, and from region to region even within the same country. Universal parameters have yet not been applied to training in pain medicine, formulation of multidisciplinary teams, or standardization of costs for pain interventions.
We designed a survey to evaluate the structure and function, as well as highlight the differences, of chronic pain services across the UK and Europe. In addition, we also set out to determine the sources of funding and the costs of common interventions across various countries in Europe to understand the health economics in pain medicine across Europe. The other aims of the survey were to gain additional information about the extent of training in pain medicine across the continent.

\section{Methods}

The survey was conducted using the online survey software and questionnaire tool "Survey monkey." The survey was open to the respondents from April through June 2011. An e-mail with a cover letter and Web link to the online survey was sent to approximately 215 pain specialists across Europe, most of whom were interventional pain specialists. A total of 82 responded, yielding an overall response rate of $38.1 \%$. However, we cannot exclude the possibility that respondents may have forwarded the survey Web link to even more colleagues. The survey consisted of 10 questions relating to the following aspects of chronic pain services in Europe.

I. Geographic distribution of pain management services

II. Clinical specialties providing pain services

III. Existence of training programs required to become a pain specialist

IV. Duration of training programs, if they exist

V. Presence of multidisciplinary clinics

VI. Specialties represented in multidisciplinary clinics, if they exist

VII. Source of funding for interventional pain procedures

VIII. Approximate hospital charges for common pain interventions

IX. As a benchmark, what is the cost (including hospital charges) for a 4 joint radio-frequency denervation?

$X$. Any other comments

All questions had either open or closed choices and the respondents could choose more than one response for the latter. Respondents were also asked to comment on and provide examples of their personal experiences relating to chronic pain services in their country. The denominator for calculating the overall percentage response was the actual number of responses given to those questions, as all responders did not complete all questions. 


\section{Results}

\section{Please indicate in which country in Europe you practice pain medicine}

Completed questionnaires were returned by 82 pain specialists from 13 countries. The bulk of the respondents (approximately 46\%) were from the UK, 12\% were from Germany, 9.5\% from Sweden, 8.3\% from the Netherlands, $7.1 \%$ from Switzerland $4.8 \%$ from Cyprus, and $2.4 \%$ from Belgium, Norway, and Finland. Other countries responding included Italy, Ireland, Portugal, and Latvia (Fig. 1).

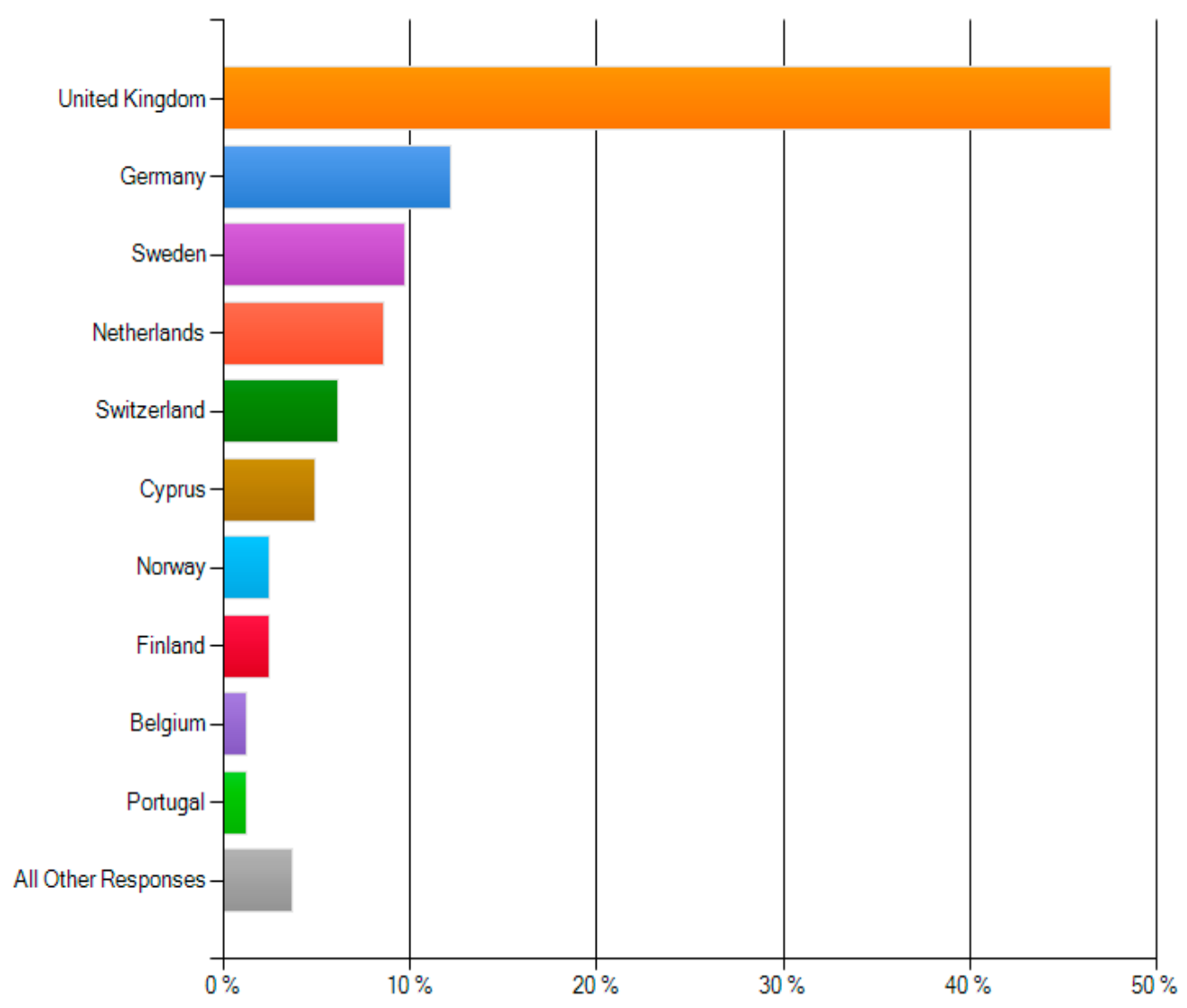

Fig. 1. Countries represented by survey takers. 


\section{Who provides pain service in your country?}

The trend of anesthesiologists being the primary provider of chronic pain services continues across Europe as is clearly evident from this survey (Fig. 2). Respondents were asked who provides chronic pain services in their country. Besides anesthesiology (100\%), other specialties which contributed to pain services included neurosurgery, as reported by $40 \%$ of the respondents, orthopedics $(33.3 \%)$, neurology $(30 \%)$, musculoskeletal $(32.1 \%)$, psychology (33.3\%), and physiotherapy (40\%). Other specialties, which $32.1 \%$ of the respondents specified, included rheumatology, general practice, palliative care, oncology, chiropractic, osteopath, rehabilitation medicine, internal medicine, and radiology.

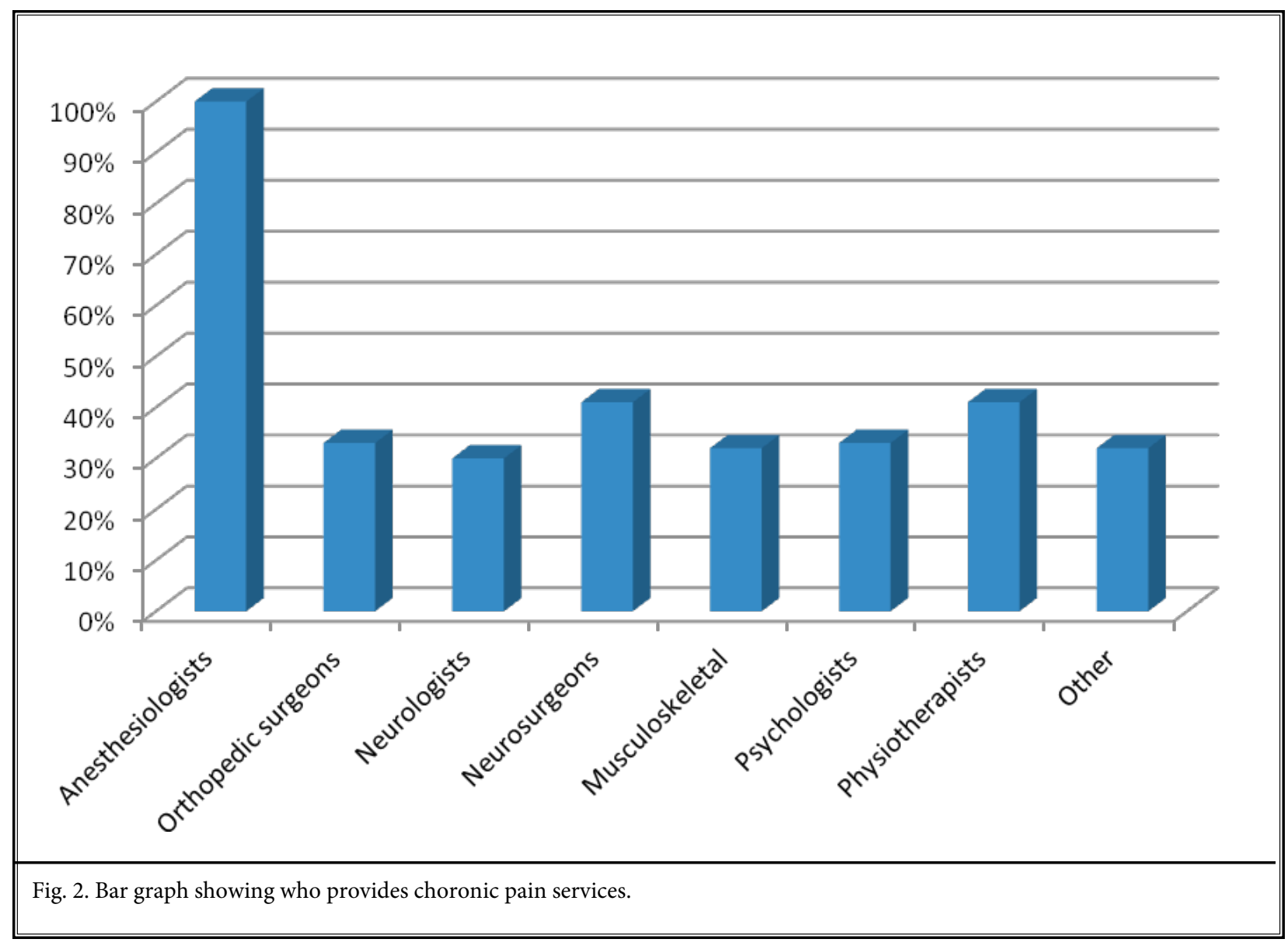




\section{Is there a training programme to become a pain specialist in your country?}

More than three-quarters $(76.2 \%)$ of the respondents reported that a training program existed in their country and it was a requirement for pain specialists (Fig. 3). From the responses we obtained, it seems that Switzerland, Belgium, and Cyprus do not have a training program for pain medicine. Respondents from Norway commented that the Scandinavian Society of Anaesthesia and Intensive Care runs a theoretical 2-year program in advanced pain management. However, the training program is for general pain management only, not for interventional pain management, which was not included in any training program.

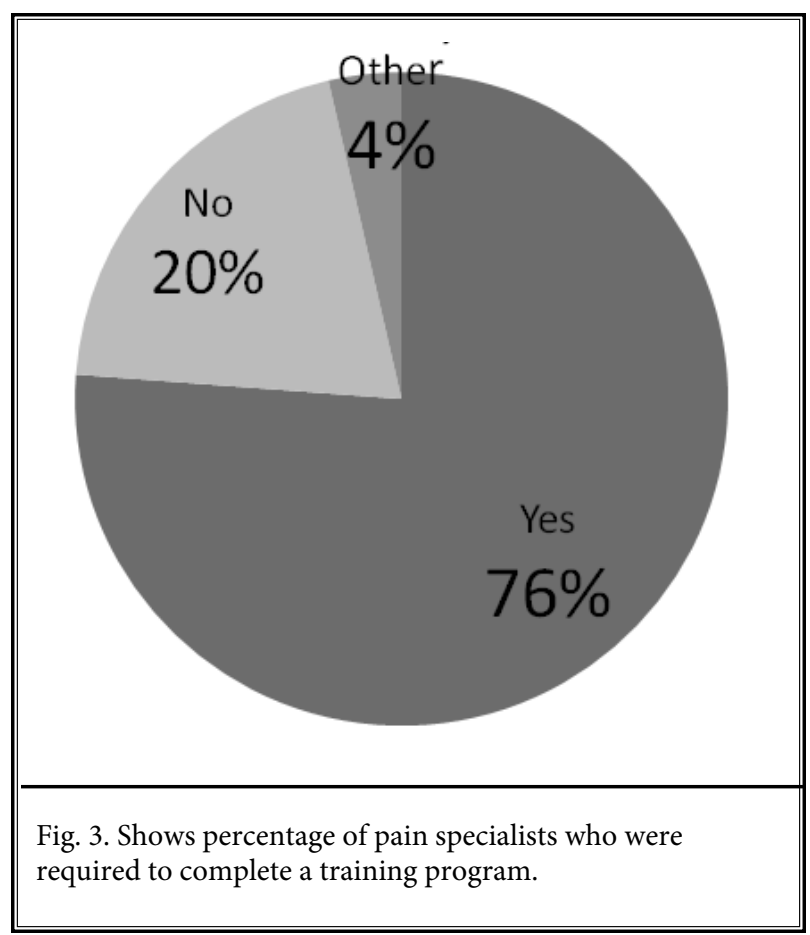

\section{If there is a training programme in your country, how much training do doctors undergo before allowing independent practice in pain medicine?}

Of the 64 respondents who reported the existence of a training program in their country, $46.3 \%$ of the respondents, mainly from the UK, Germany, and Sweden, replied that the training program duration was at least 12 to 18 months before doctors were allowed independent practice. A minimum training duration of 6-12 months was reported by $23 \%$ of the respondents, again mainly from the UK and some from the Netherlands. A training program duration of more than 18 months was reported by $26.2 \%$, mainly from Finland, Ireland, Germany, and the UK. Hence, on average, the majority of European nations train their doctors for at least one year before they are allowed independent practice in pain medicine. Only 4 respondents replied that their training period duration was less than 6 months. Of these 4, one respondent from the Netherlands commented that they had a 3-month postgraduate pain certification course during anesthesiology residency.

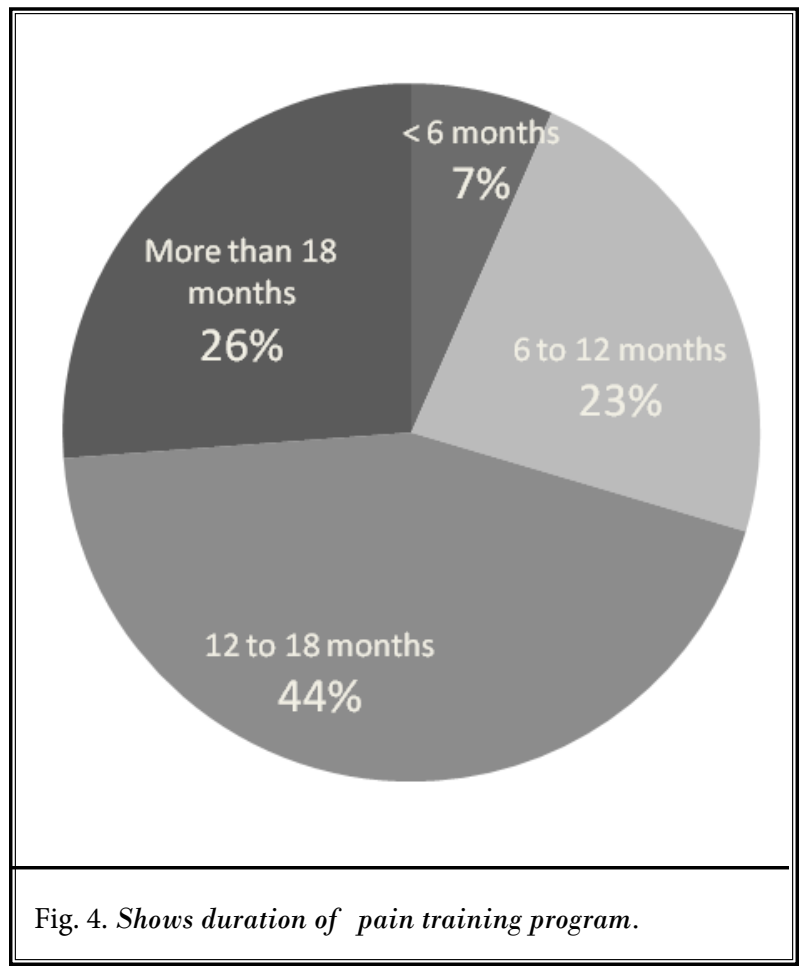




\section{Do you work in a multidisciplinary team?}

Among the 82 respondents, $70 \%$ worked within a multidisciplinary team and $24 \%$ did not (Fig. 5). A few respondents (6\%) reported that they had access to others but did not work as a team and involved them only when necessary, or when they had seen the patient themselves and done diagnostic precision blocks.

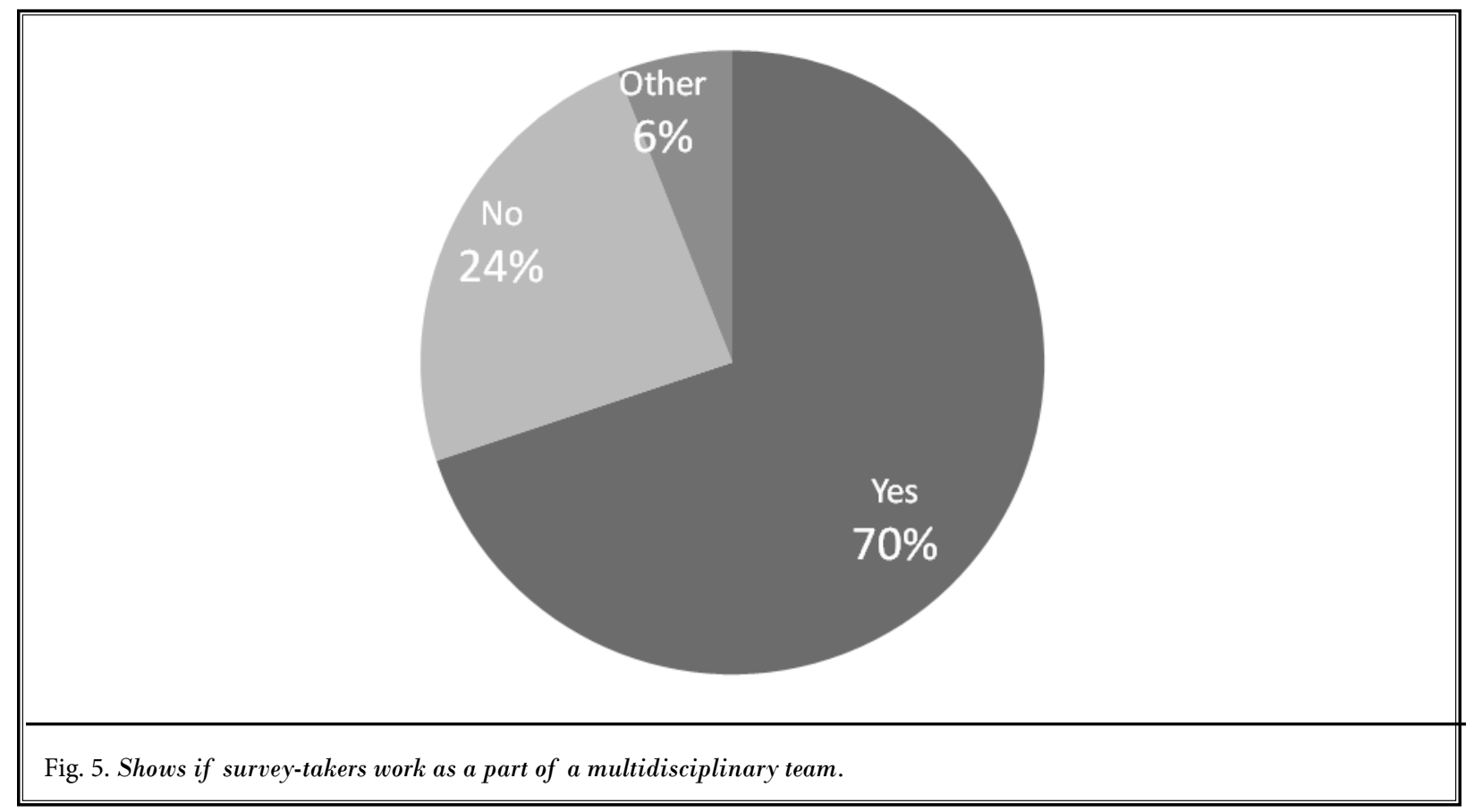

\section{If you work within a multidisciplinary team, which specialties are represented?}

We asked the respondents who work in a multidisciplinary team to indicate what personnel comprised the typical team. The majority of respondents indicated physiotherapists $(82.8 \%)$, pain specialist $(85.9 \%)$ along with specialist pain nurses $(75 \%)$ as the most important and frequent members of any team. The second most frequently reported members of the team were occupational therapists $(35.9 \%)$, spine surgeons $(34.4 \%)$, and pharmacists $(14.1 \%)$. A little more than one-fifth, $21.9 \%$ of the respondents, also reported people from other disciplines involved in the team. These included neurologists, neurosurgeons, rehabilitation specialists, psychiatrists, podiatrists, osteopaths, radiologists, palliative care specialists, urologists, colorectal surgeons, and gynecologists interested in pelvic pain (Fig. 6). 


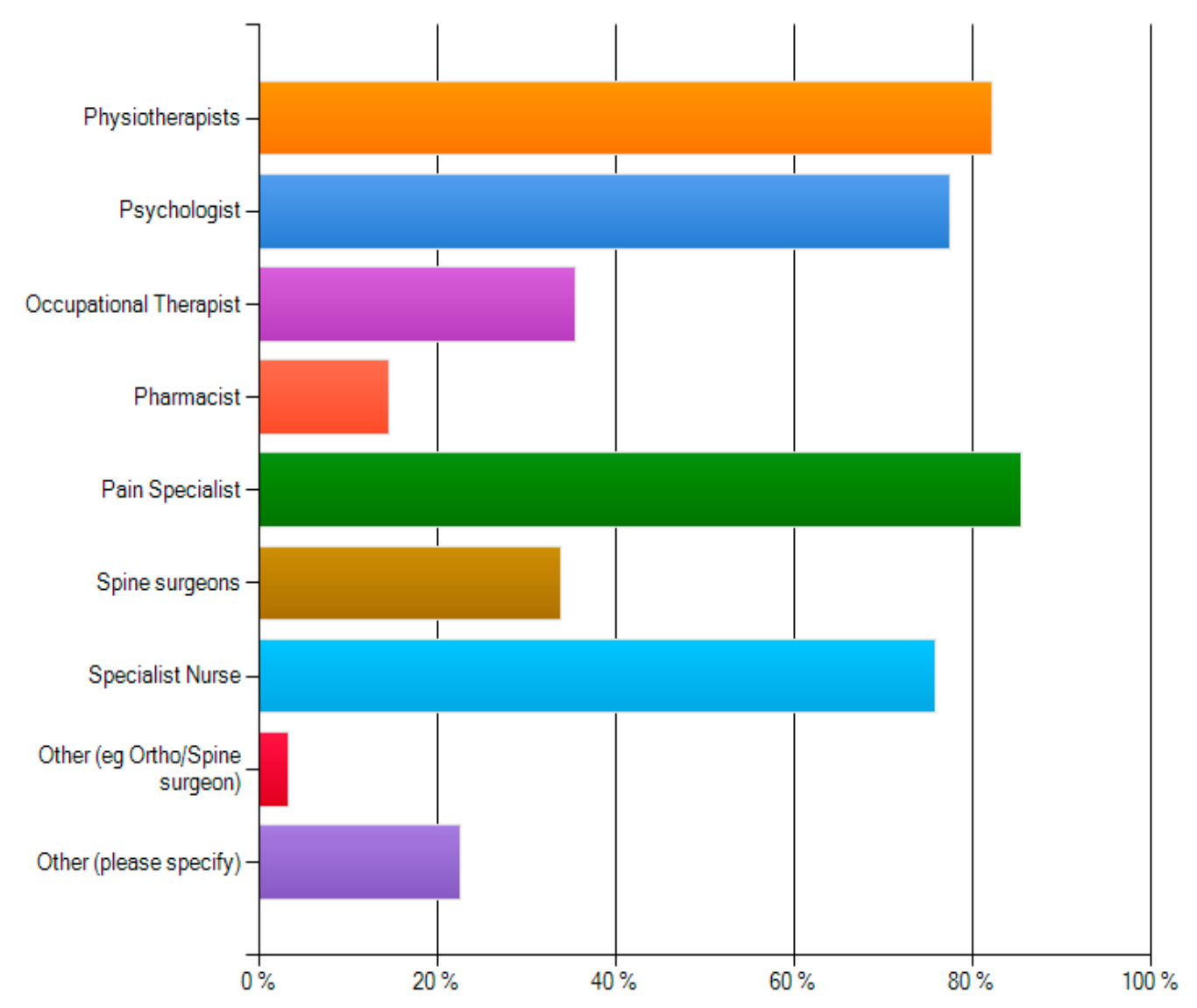

Fig. 6. Shows specialities represented in multidisciplinary teams.

\section{Who pays for interventional pain procedures in your country?}

In response to the question on funding sources for interventional pain procedures (Fig. 7), $71.1 \%$ reported government-financed services in their countries. These were the UK, Ireland, Sweden, Norway, and Finland, whereas Germany, Switzerland, and the Netherlands had insurance funding. Alternative sources of funding were self-funding when necessary, reported by $36.1 \%$ of the respondents. Other sources mentioned were accident compensation funds, state pension funds, and local hospitals. One of the respondents from Switzerland mentioned that not all interventional techniques are reimbursed by insurance companies, so these procedures are performed without reimbursement. 


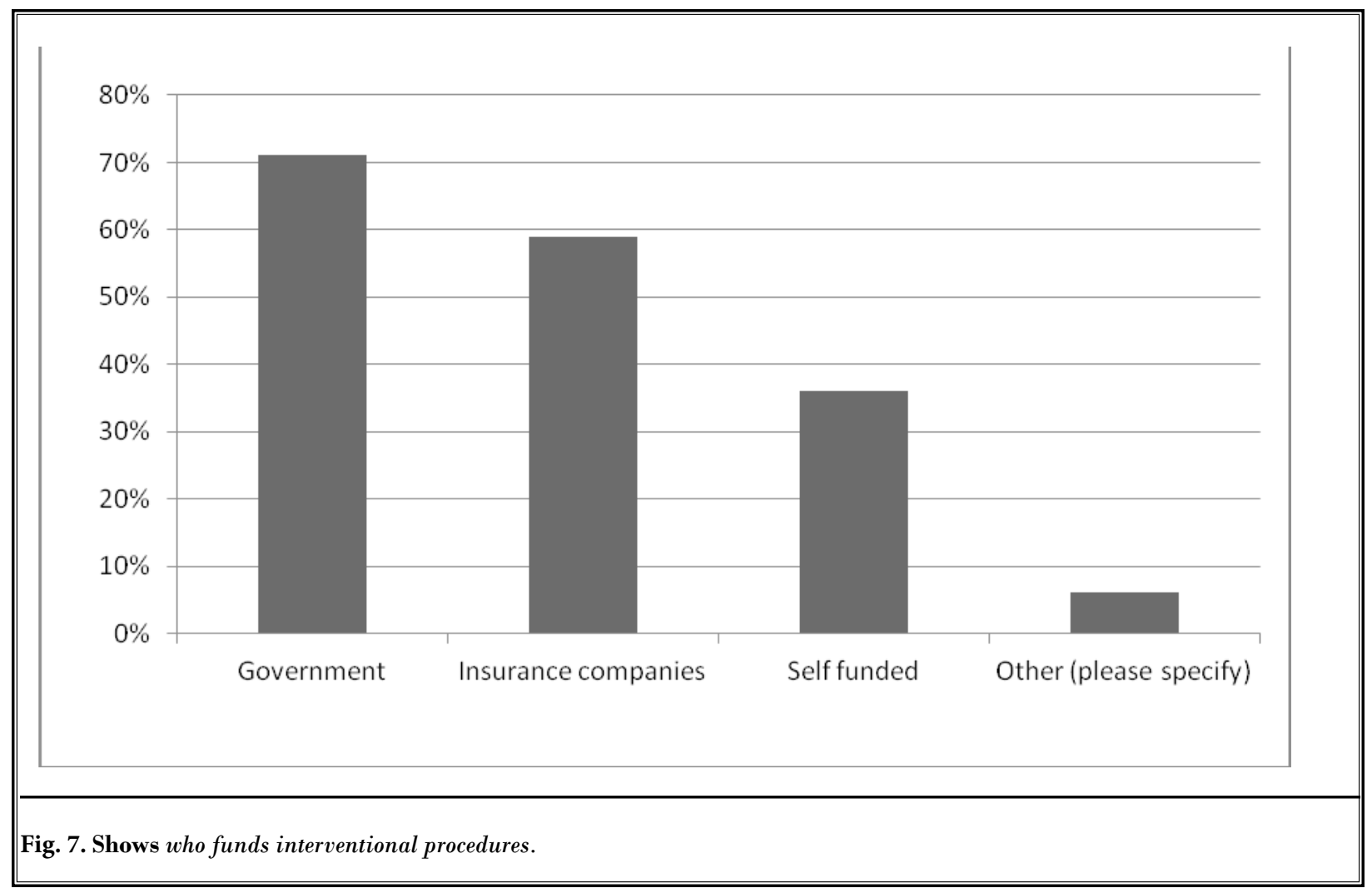

\section{As a guide and average how much does the hospital charge the patient or insurers for the following procedures?}

In order to understand the variation in health economics, we included a question in the survey asking about the total cost of interventions, including hospital charges, specialist fees, and administration charges. One GBP (British pound sterling) was taken as equivalent to one Euro for conversion purposes. The responses are shown in Fig. 8. More than two-thirds of the respondents reported the total cost of caudal epidural steroid injection (ESI) to be less than $€ 500$ (\$645). For transforaminal ESI, 3 level medial branch blocks, 6 levels facet joint injections and cervical ESI, about half of the respondents reported the total costs to be less than $€ 500$.

Though the survey did not specifically ask about how the insurance-based system determined the costs for interventions, some respondents mentioned some interesting facts. In the Netherlands, the insurance system is DBC module which is a casemix-based funding model: payment is made for the total treatment for a given diagnosis, irrelevant of how many treatments are needed. "DBC" (Dutch: Diagnosebehandelcombinatie) can be defined as a predefined average care package, which is applied with a fixed price related to a specific diagnosis. For example, the total cost of treatment for degenerative lumbar pain, including outpatient visits and invasive treatments, is about $€ 1,000$ ( $\$ 1,290)$. Three or 4 treatments repeated over one year could cost around $€ 3,500(\$ 4,515)$ in that year. There are different DBCs for low back, thoracic, and cervical pain.

The German insurance system determines the costs using the diagnosis-related-groups (DRG) system. This is also a casemix-based model. It classifies acute inpatient episodes into a number of manageable categories based on clinical condition and resource consumption. A single acute episode of inpatient care is allocated to one DRG using coded clinical information derived from the patient's medical record. For most pain interventions, an all-inclusive DRG for a minimum stay of 3 days is approximately $€ 2100(\$ 2,709)$, independent of whether the patient gets an intervention or just physiotherapy. The reimbursement is very low for outpatient interventional pain procedures. 
For example, reimbursement for facet joint injections, or any kind of ESI is about $€ 100$ ( $\$ 129)$ for patients with standard insurance and about 3 times more for patients with private insurance. In Sweden, the patient is charged 300 kronor or approximately $€ 30$ (\$39); the rest is paid by the government. The UK National Health Service (NHS) tariff is based on the health-related groups (HRG) system, and the typical cost to the NHS for an epidural is $f 500$ $(\$ 804)$ and $f 600-£ 1,000(\$ 964-\$ 1,607)$ if insured.

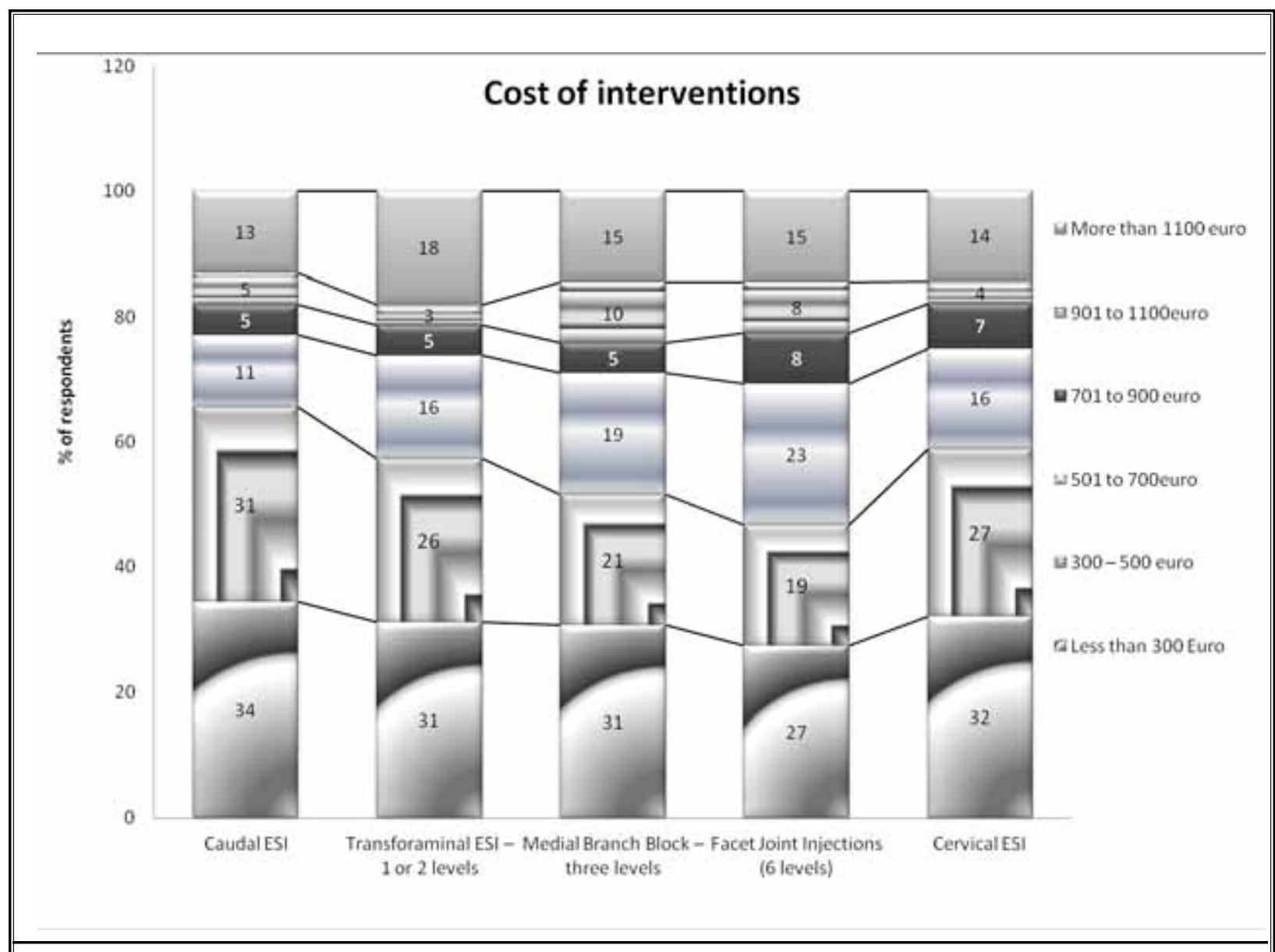

Fig. 8. Responses showing average hospital charge to patients and insureres following procedures 


\section{What is the total cost (including hospital charges) of 4 joints lumbar Radiofrequency Denervation procedure?}

We also asked the respondents to indicate the total cost of a 4 joint lumbar radiofrequency (RF) denervation procedure (Fig. 9). Less than $€ 1,000$ ( $\$ 1,290)$, which is the standard UK NHS tariff, was selected by $42.6 \%$ of the respondents. Approximately the same percentage $(42.7 \%)$ of respondents indicated the cost to be between $€ 1,000$ $€ 2,000(\$ 1,290-\$ 2,580)$; the insurance-based tariff in the UK falls within this range. In Switzerland, RF denervation is not reimbursed by the insurance companies. In Ireland, the tariff is $€ 630$ (\$813), however if repeated the cost is $€ 361$ (\$466). In Germany, RF denervation is done as an inpatient procedure, and the DRG for the average 3-5 day inpatient stay is $€ 2,100(\$ 2,709)$.

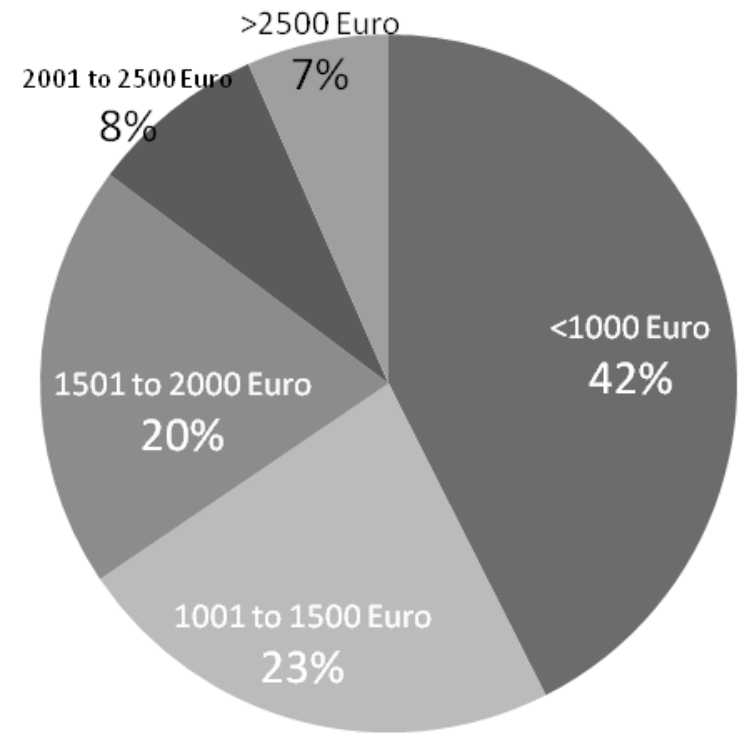

Fig. 9. Shows the total cost of 4 joints lumbar radiofrequency denervation procedure. 


\section{$\mathbf{X}$ \\ Please write below anything else you will like to add that has not been included in the survey?}

Lastly, we asked the respondents to include what they thought was missing from the survey and to add their own opinions and comments. Respondents from Norway acknowledged their service is underdeveloped in this field. No hospital in Norway can do interventional pain procedures. There are only 3 pain physicians serving a population of approximately 5 million. They have had to invest in facilities and equipment themselves at their own cost. This probably correlates with the fact that the prevalence of chronic pain was highest in Norway in the findings of the European pain survey (1). In contrast, neighboring Sweden has a system which allows patients to have access to all pain services at a cost of only $€ 30$ (\$39). Pain clinics and multidisciplinary teams for chronic nonmalignant pain are almost nonexistent in Cyprus. However, for adult cancer patients, pain is managed within a multidisciplinary approach by palliative care doctors and is provided free of charge by the government without any form of means testing.

\section{Discussion}

Chronic pain is a common and distressing condition. There are not many studies evaluating the structure and function of pain services in Europe. It is known from previous reports that there is a wide variation in the availability of chronic pain services from hospital to hospital and region to region within the UK (2). There could also be a significant difference in the funding and staffing levels among hospitals in the UK. This survey confirms even more significant variations in the structure and function of pain services across Europe. There was little consistency either in the treatments available, source of funding, and costs for the same treatment. There was no common element in the training offered to become a pain specialist.

This survey indicates that chronic pain interventions are primarily funded either through government or insurance companies. The primary chronic pain service members continue to be anesthesiologists, combined with specialist nurses and physiotherapists. The expertise of anesthesiologists in pain management explains their significant involvement in chronic pain. There appears to be a lack of consistency with regards to working in a multidisciplinary team, even if systematic reviews provide good evidence of efficacy for pain management programs and multidisciplinary teams (11).

There is wide variation in the amount and time of training received by pain trainees across Europe; training is inadequate in some countries, especially given the burden of pain in the general population. There is clearly a need to increase the time trainees spend while training to become a pain physician. Rigorous assessments of competency in pain medicine have been developed by the Faculty of Pain Medicine of the Royal College of Anaesthetists in the UK (5). The provision of training in pain medicine should be supervised, and all countries should have a faculty which could develop rigorous assessments of competencies in pain management. Good practice should ensure adequate training and ongoing education of all staff. Finally, the considerable cost variations for common interventions among different centers observed in this survey could be further evaluated.

\section{Conclusion}

It is important to realize that this survey has a demographic limitation of a relatively high representation by pain specialists from the UK. The overall response rate was about $38.1 \%$; hence we had limited means of determining how respondents differed from nonrespondents. The survey was kept short to increase responses. Despite these limitations, the survey does provide some valuable insights into the current structure of chronic pain services across Europe. This could provide some guidance for improving chronic pain services. A more detailed, large scale survey is perhaps required to map the availability of chronic pain services in terms of a wide range of issues, including the size of the services (staff, equipment, and patient numbers), treatments offered, facilities and equipment available, interdisciplinary relationships, and training of pain physicians. 


\section{References}

1. Breivik H, Collett B, Ventafridda V, Cohen R, Gallacher D. Survey of chronic pain in Europe: Prevalence, impact on daily life and treatment. Eur J Pain 2006; 10:287-333.

2. "drfoster"; British Pain Society. Adult chronic pain management services in the UK. www.britishpainsociety.org/dr_ foster.pdf

3. Department of Health, Chief Medical Officer's Annual Report. Department of Health, United Kingdom, 2008 www.dh.gov.uk/en/Publicationsandstatistics/Publications/AnnualReports/ DH_096206

4. Beeck L, Hermans V. Research on work related low back disorders. European
Agency for Safety and Health at Work, Brussels, 2000.

5. Andersson G. Epidemiological features of chronic low-back pain. Lancet 1999; 354:581-585.

6. Van Tulder M, Koes B and Bouter L. A cost-of-illness study of back pain in The Netherlands. Pain 1995; 62:233-240. 7. Manchikanti L. Epidemiology of low back pain. Pain Physician 2000; 3:167-192.

8. Manchikanti L, Boswell MV, Singh V, Benyamin R, Fellows B, Abdi S, Buenaventura, Conn A, Datta S, Derby R, Falco F, Erhart S, Diwan S, Hayek SM, Allan T, Smith $H$. Comprehensive evidencebased guidelines for interventional techniques in the management of chronic spinal pain. Pain Physician 2009; 12:699802.

9. Manchikanti L, Boswell MV, Datta S, Fellows B, Abdi S, Singh V, Benyamin RM, Falco F, Helm S, Hayek S, Smith H. Comprehensive review of therapeutic interventions in managing chronic spinal pain. Pain Physician 2009; 12:E123E198.

10. Manchikanti L, Buenaventura RM, Manchikanti K, Ruan X, Gupta S, Smith HS, Christo PJ, Ward SP. Effectiveness of therapeutic lumbar transforaminal epidural steroid injections in managing lumbar spinal pain. Pain Physician 2012; 15:E199-E245. 